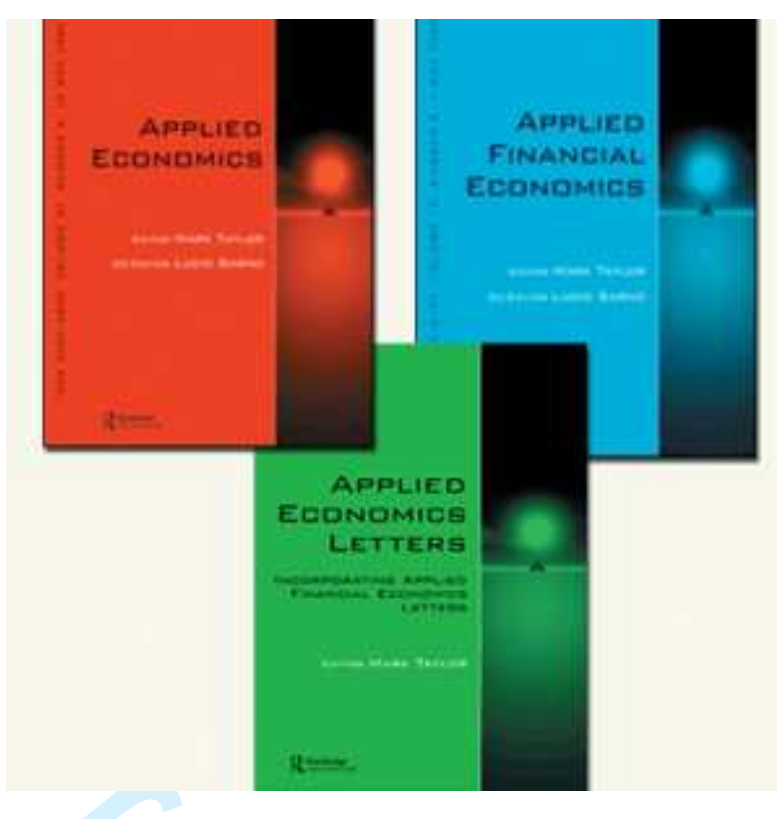

\title{
Long-run relationships between international stock prices: further evidence from fractional cointegration tests
}

\begin{tabular}{|r|l|}
\hline Journal: & Applied Economics \\
\hline Manuscript ID: & APE-2010-0212 \\
\hline Journal Selection: & Applied Economics \\
\hline Date Submitted by the & Au-Apr-2010 \\
\hline Complete List of Authors: & $\begin{array}{l}\text { Aloy, Marcel; DEFI, Université de la Méditerranée } \\
\text { Mohamed, BOUTAHAR; Université de la Méditerranée, GREQAM } \\
\text { GENTE, Karine; Université de la Méditerranée, DEFI } \\
\text { PEGUIN-FEISSOLLE, Anne; GREQAM }\end{array}$ \\
\hline JEL Code: & $\begin{array}{l}\text { C12 - Hypothesis Testing < C1 - Econometric and Statistical } \\
\text { Methods: General < C - Mathematical and Quantitative Methods, } \\
\text { C22 - Time-Series Models < C2 - Econometric Methods: Single } \\
\text { Equation Models < C - Mathematical and Quantitative Methods, F31 } \\
\text { - Foreign Exchange < F3 - International Finance < F - International } \\
\text { Economics, F37 - International Finance Forecasting and Simulation } \\
<\text { F3 - International Finance < F - International Economics, G15 - } \\
\text { International Financial Markets < G1 - General Financial Markets < } \\
\text { G - Financial Economics }\end{array}$ \\
\hline Keywords: & \begin{tabular}{l} 
equity markets, fractional cointegration, long memory \\
\hline
\end{tabular} \\
\hline
\end{tabular}




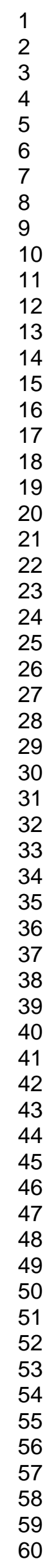

5) ScholaroNE"

25

26

27

29

30

31

33

34

35

36

37

39

40

41

42

43

44

46

47

48

49

50

(51 


\title{
Long-run relationships between international stock prices: further evidence from fractional cointegration tests
}

\author{
Marcel Aloy* Mohamed Boutahar ${ }^{\dagger}$ Karine Gente ${ }^{\ddagger}$ \\ Anne Péguin-Feissolle ${ }^{\S}$
}

April 28, 2010

\begin{abstract}
The recent empirical literature supports the view that most of the international stock prices are not pairwise cointegrated. However, by using fractional cointegration techniques, this paper shows that France, Germany, Hong Kong, and Japan stock prices indices are pairwise fractionally cointegrated with US stock prices. Equilibrium errors are mean reverting with half-life lying between 2 and 12 days. It is worthwhile noting that emerging markets like Brazil and Argentina are not pairwise cointegrated with the US stock market. These new results have important implications for asset pricing and international portfolio strategy.
\end{abstract}

Keywords: equity markets, fractional cointegration, long memory

JEL classification: C12, C22, F31, F37, G15.

* DEFI, Université de la Méditerranée, Faculté des Sciences Economiques et de Gestion, 14 Avenue J. Ferry, 13621 Aix-en-Provence, FRANCE, Email: marcel.aloy@univmed.fr

${ }^{\dagger}$ Corresponding author: Mohamed Boutahar, GREQAM, Université de la Méditerranée, Centre de la Charité, 2 rue de la Charite, 13236 Marseille cedex 02, FRANCE, Email: mohammed.boutahar@univmed.fr

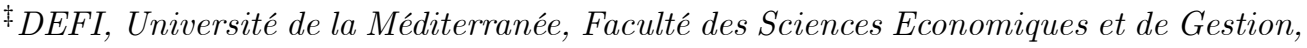
14 Avenue J. Ferry, 13621 Aix-en-Provence, FRANCE, Email: karine.gente@univmed.fr

$\S$ GREQAM, CNRS, Centre de la Charité, 2 rue de la Charite, 13236 Marseille cedex 02, FRANCE, Email: Anne.Peguin@univmed.fr 


\section{Introduction}

A great number of papers have used cointegration techniques to examine the long-run relationships between international stock prices, motivated by the fact that cointegration between stock prices has several important implications for asset pricing. Firstly, cointegration between prices of some national stock markets implies that these markets share a common stochastic trend. As a consequence, potential benefits from long run diversification will be reduced since deviations of one market away from the equilibrium relationship can be expected to reverse geometrically over the long run. Secondly, as stated by Granger (1986), evidence of cointegration among world capital markets may lead to the rejection of the efficient markets hypothesis since cointegration induces short run predictability of prices via the error correction mechanism; however, Richards (1995), among others, argues that cointegration among stock prices may not necessarily imply violation of market efficiency. Thirdly, some researchers have documented the long-run predictability of prices through the Winner-Loser reversal effect (Richards, 1995) which states that markets that have experienced superior performance can be expected to underperform over the longer term, and vice versa.

On the empirical side, the literature analyzing the long-run relationships between international stock markets has produced mixed results. Some papers (Kasa, 1992, Corhay et al., 1993, Dunis and Shannon, 2005; Fraser and Oyefeso, 2005; Diamandis, 2009) found at least one common stochastic trend between international stock indices using Johansen's (1988) multivariate linear cointegration tests. However, the recent literature generally supports the view that most of the international stocks are not linearly pairwise cointegrated (Chan et al., 1997; Kanas, 1998; Pynnönen and Knif, 1998; Huang and Fok, 2001; Davies, 2006; Li, 2006; Olusi and Abdul-Majid, 2008) or that the evidence for multivariate cointegration is weak ${ }^{1}$ (Ahlgren and Antell, 2002). Focusing on UK (Taylor and Tonks, 1989), European stock markets (Rangvid, 2001; Garcia Pascual, 2003; Bley, 2009) or Pacific-Basin countries (Phylaktis and Ravazzolo, 2005), some papers suggest moreover that the integration process of financial markets may be time and/or country dependent.

An important reason for these mixed results is that usual linear testing techniques may be inadequate in presence of non-standard dynamics, such as nonlinearity or structural change. Therefore, Li (2006) applies rank test for non linear cointegration while Davies (2006) uses regime switching cointe-

\footnotetext{
${ }^{1}$ Ahlgren and Antell (2002) and Richards (1995) point out that some of the previous empirical results can be explained by the small-sample bias and size distortion of Johansen's LR tests for cointegration. Moreover, they underline the fact that Johansen's tests appear to be sensitive to the lag length specification in the VAR model.
} 
gration techniques and Huang and Fok (2001) suggest that markets may be temporally cointegrated by using tests related to the stochastic permanent breaks model.

The aim of this paper is to provide further evidence on the pairwise linkages between the US and some of the major foreign equity markets by taking into account the fractional cointegration hypothesis ${ }^{2}$. According to this hypothesis, the cointegration errors tend to revert back hyperbolically (and not geometrically) to some mean (or deterministic trend): as in the standard cointegration framework, fractional cointegration introduces arbitrage opportunities, since there is some predictability of prices in the longrun (Winner-Loser effect) as well as in the short-run (through the fractionally error-correction mechanism suggested by Granger, 1986). However, in a strategic asset allocation perspective (in the sense of Lucas, 1997), fractional cointegration reduces the gain of portfolio diversification.

In this paper we consider France, Germany, UK and Japan equity markets and some emerging countries' equity markets like Argentina, Brazil and Hong Kong. We will proceed in three steps. The first step consists in investigating the order of integration of each national stock index. In a second step, we use the strategy of Gil-Alana (2003) and Caporale and Gil-Alana (2004a, 2004b) to consider the possibility of the series being pairwise fractionally cointegrated. The third step consists in measuring the persistence of shocks for countries whose stock markets are related to the US one in the long-run. We confirm that all stock index series we consider are non-stationary I(1). Except for Germany, we find no standard cointegration between US stock market and the foreign stock markets into consideration, as already stated by Kanas (1998) for the case of France and UK. However, we conclude that the US stock market is fractionally cointegrated with the French, German, Japanese, UK and Hong Kong stock market indices. Conversely, the relationship is neither significant for the US stock market and the Argentinian index, nor for the US stock market and the Brazilian index. The persistence is measured by the half-lives which lie between 1.88 and 11.88 days, depending on the country considered. The highest half-life is the Japanese one, the lowest being the French one.

The rest of the paper is organized as follows. The next section presents the econometric method for detecting fractional integration and cointegration. The empirical application is carried out in Section 3 while Section 4 contains some concluding comments.

\footnotetext{
${ }^{2}$ The paper of Pynnönen and Knif (1998) constitutes a first attempt to apply the fractional cointegration hypothesis in the case of stock markets. Using the Cheung and Lai's (1993) fractional cointegration test in the case of two scandinavian stock markets, the authors found no evidence of fractional cointegration.
} 


\section{The econometric approach}

\subsection{Fractional integration and cointegration}

A time series $y_{t}$ follows an $A R F I M A(p, d, q)$ (autoregressive fractionally integrated moving average) process if

$$
\Phi(L)(1-L)^{d} y_{t}=\mu+\Theta(L) \varepsilon_{t},
$$

with

$$
\Phi(L)=1-\phi_{1} L-\ldots-\phi_{p} L^{p}, \Theta(L)=1+\theta_{1} L+\ldots+\theta_{q} L^{q},
$$

$L$ is the Backward shift operator i.e. $L y_{t}=y_{t-1}$ and $\varepsilon_{t} \sim i i d\left(0, \sigma^{2}\right)$. Different cases are possible, depending on the value of the long memory parameter $d$; for example, $y_{t}$ is stationary and possesses shocks that disappear hyperbolically when $0<d<1 / 2$, but is non-stationary and mean reverting for $1 / 2 \leq d<1$. Moreover, fractional cointegration can be defined as follows. Let us consider two time series $y_{t}$ and $x_{t}$ that are both $I(d)$, where $d$ is not necessarily an integer; $y_{t}$ and $x_{t}$ are fractionally cointegrated when the residuals, defined by $e_{t}=y_{t}-\beta x_{t}$, are $I(d-b)$ with $b>0$, where $b$ is also not necessarily an integer. There is a growing literature dealing with fractional cointegration $^{3}$.

We use here the methodology elaborated by Robinson (1994) for testing unit root and other nonstationary hypotheses. Let us consider the null hypothesis defined by $H_{0}: \theta=0$ in the model given by $y_{t}=\beta^{\prime} X_{t}+e_{t}$ and $(1-L)^{d+\theta} e_{t}=u_{t}$, for $t=1,2, \ldots$, where $y_{t}$ is the observed time series, $X_{t}$ is a $k \times 1$ vector of deterministic regressors, $u_{t}$ is a (possibly weakly autocorrelated) $I(0)$ process, and $d$ is a real parameter. The Lagrange Multiplier (LM) statistic proposed by Robinson (1994), called $\widehat{r}$ (see Appendix for details) has a standard asymptotic distribution under some regularity conditions: $\widehat{r} \underset{d}{\longrightarrow} N(0,1)$ as $T \longrightarrow \infty$. Thus, it is a one-sided test of $H_{0}: \theta=0:$ we reject $H_{0}$ against $H_{1}: \theta>0$ if $\widehat{r}>z_{\alpha}$ and against $H_{1}: \theta<0$ if $\widehat{r}<-z_{\alpha}$, where the probability that a standard normal variate exceeds $z_{\alpha}$ is $\alpha$. This Robinson (1994)'s test has been used in several papers in order to detect fractional integration ${ }^{4}$.

\footnotetext{
${ }^{3}$ For instance, see among others Baillie and Bollerslev (1994), Caporale and Gil-Alana (2004a and b), Cheung and Lai (1993), Christensen and Nielson (2006), Davidson (2005), Dittman (2001), Hassler, Marmol and Velasco (2006), Kim and Phillips (2001), Marinucci and Robinson (2001), Nielsen (2006), Robinson and Marinucci (2003), Robinson and Yajima (2002), Tse, Anh and Tieng (1999), Velasco (2003).

${ }^{4}$ Among others: Caporale and Gil-Alana (2004a and b, 2007a and b), Gil-Alana (2003), and Gil-Alana and Nazarski (2007).
} 
In order to detect the cointegration, we adopt the two-step strategy of Gil-Alana (2003) and Caporale and Gil-Alana (2004a and b) based on the Robinson $(1994)^{5}$ test: in the first step, we test the order of integration of each series, and if they are of the same order, we test, in the second step, the order of integration of the estimated residuals of the cointegration relationship. Gila-Alana (2003) and Caporale and Gil-Alana (2004a) note that the ordinary least squares (OLS) estimation of the equilibrium error can produce an estimator which may suffer from second-order bias in small samples, but they choose to use it on the grounds of simplicity; in this paper, the sample sizes are enough large to neglect this problem. Let us call $e_{t}$, the estimated equilibrium errors between two series $y_{t}$ and $x_{t}$ (this can be easily generalized to more series): $e_{t}=y_{t}-\widehat{\beta} x_{t}$ where $\widehat{\beta}$ is the OLS estimator of the cointegrating parameter. Let us consider the model: $(1-L)^{d+\theta} e_{t}=u_{t}$ where $u_{t}$ is a $I(0)$ process ; we applied the Robinson (1994)'s testing procedure in order to test the null hypothesis $H_{0}: \theta=0$ against the alternative $H_{1}$ : $\theta<0$. If the null hypothesis is rejected, it implies that the equilibrium error exhibits a smaller degree of integration than the original series: $y_{t}$ and $x_{t}$ are thus fractionally cointegrated. On the opposite, if the null hypothesis is not rejected, we will admit that the series are not cointegrated because the order of integration of $e_{t}$ is the same as the order of the original series.

\subsection{Half-life analysis}

One way to estimate the persistence of the estimated residuals from the cointegration regression is to fit an ARFIMA model to $e_{t}$ and then estimate its impulse response function. By allowing the long memory parameter $d$ to take non-integer values, the fractional model accommodates a broader range of low-frequency, mean-reverting dynamics than do standard time series models.

The mean-reverting property holds if $d<1$ whereas the impact of a shock is known to persist forever in case of a unit-root process: $d=1$. This can be

\footnotetext{
${ }^{5}$ Gil-Alana (2003) conducts Monte-Carlo experiments in order to examine the size and power properties of the Robinson's (1994) test relative to the usual Engle-Granger's ADF and the Geweke \& Porter-Hudak tests, the later being used by Cheug and Lai (1993) in order to test fractional cointegration.

These experiments show that Robinson's (1994) tests perform better than the ADF and GPH tests both in term of power and size. As stated by Gil-Alana (2003), "the difference in power between Robinson's (1994) and the ADF and GPH tests for cointegration should not be surprising given that the ADF test assumes a strict $\mathrm{I}(0)$ and $\mathrm{I}(1)$ distinction and the GPH test requires estimation of the differencing parameter, whereas Robinson (1994) tests do allow fractional differencing and do not require estimation of the fractional differencing parameter".
} 
seen from the moving average representation for $(1-L) e_{t}=A(L) \varepsilon_{t}$ where

$$
\begin{gathered}
A(L)=(1-L)^{1-d} \Psi(L)=1+a_{1} L+a_{2} L^{2}+\ldots \\
\Psi(L)=1+\psi_{1} L+\psi_{2} L^{2}+\ldots
\end{gathered}
$$

The moving average coefficients $a_{j}, j=1, \ldots$, are referred to as the impulse responses and can be computed as follows:

$$
a_{j}=\sum_{k=0}^{j} \frac{\Gamma(k+d-1)}{\Gamma(d-1) \Gamma(k+1)} \psi_{j-k},
$$

where the $\left(\psi_{j}\right)$ can be computed recursively:

$$
\psi_{0}=1, \psi_{j}=\theta_{j}+\sum_{i=1}^{\min (j, p)} \phi_{i} \psi_{j-i} \quad \text { if } \quad 1 \leq j \leq q
$$

and

$$
\psi_{j}=\sum_{i=1}^{\min (j, p)} \phi_{i} \psi_{j-i} \quad \text { if } \quad j \geq q+1 .
$$

The cumulative impulse response function over $j$ periods of time is given by $C_{j}=1+a_{1}+\ldots+a_{j}$ and it tracks the impact of a unit innovation at time $t$ on the long run equilibrium relationship at time $t+j$. As $j \rightarrow \infty C_{\infty}=A(1)$, measuring the long-run impact of the innovation (Campbell and Mankiw, 1987). Cheung and Lai (1993) show that for $d<1, C_{\infty}=0$, implying shockdissipating behavior. Conversely for $d \geq 1, C_{\infty} \neq 0$, the effect of a shock will not die out. Mean reversion (i.e. $C_{\infty}=0$ ) occurs as long as $d<1$. A measure of persistence usually considered in the literature is the half-life, which indicates how long it takes after a unit shock to dissipate by half on the long-run equilibrium. The half-life can be computed from the $C_{j}$ function as $t=h$ at where $C_{h}=0.5$. For ARMA models, an analytical expression for the half-life can be derived; for example, it is well known that the halflife of the $\operatorname{AR}(1)$ model $e_{t}=\phi e_{t-1}+\varepsilon_{t}$ is given by $h=-\log (2) / \log (\phi)$. However, for the ARFIMA model, the half-life remains difficult to compute. This problem can be solved plotting the impulse response function and using linear interpolation.

\section{$3 \quad$ Empirical analysis}

\subsection{The data}

The different series are the daily closing values for the following stock indices: $B O V$ (Bovespa, Brazil), CAC (CAC 40, France), DAX (Dax, Germany), 
FTSE (FTSE 100, UK), HS (Hang Seng, Hong Kong), NK (Nikkei 225, Japan), MERV (Merval, Argentina) and SP (Standard and Poor's 500, USA). We consider the log-transformed daily data over the period January 4, 1999 - March 6, 2008 ( $T=2389$ where $T$ is the sample size). The logtransformed daily series over the whole period are plotted in Figure 1 (the descriptive statistics of the returns are given in Table 1).

[Insert Table 1 here]

[Insert Figure 1 here]

\subsection{Empirical results}

\subsubsection{Integration analysis of individual series}

The first step in the empirical analysis is to investigate the order of integration of the individual series. We first perform the Kwiatowski, Phillips, Schmidt and Shin (1992) (KPSS) test for unit root, where the null hypothesis is the stationarity, on the raw series and on the first differenced series. The results are reported in Table 2 and clearly show the rejection of the null hypothesis by the KPSS test on the raw series and the non-rejection of the null hypothesis on the differenced series, which means that all the log-transformed daily series contain a unit root.

[Insert Table 2 here]

Table 3 summarizes the results of the FELW estimation procedure (Shimotsu (2006)) of the long memory parameter $d$, for the different series; $\widehat{d}$ are the estimators of $d$ and $\widehat{\sigma}$ are the estimated standard-errors; $d_{l}$ and $d_{u}$ are the lower and upper bounds of the confidence intervals, respectively $\widehat{d}-1.96 \widehat{\sigma}$ and $\widehat{d}+1.96 \widehat{\sigma}$. The orders of integration lies between 0.964 and 1.080, and the unit value lies always in the $95 \%$ confidence intervals, whatever the series; it confirms again that the series contain a unit root, i.e., the null $d=1$ cannot be rejected.

\section{[Insert Table 3 here]}

Table $4{ }^{6}$ shows the results of the statistic $\widehat{r}$ of the Robinson (1994)'s tests applied to each individual series. Different values of $d$ are considered, thus testing for a unit root $(d=1)$ but also other fractional possibilities. We

\footnotetext{
${ }^{6}$ The authors thank Luis A. Gil-Alana for providing various FORTRAN programs for the Robinson (1994)'s test, that they translated in GAUSS.
} 
can observe that the minimum of the absolute values of the Robinson (1994) test statistic occurs always when $d=0.95$ or 1 (and 1.05 for $M E R V$ ). This permits to conclude that all the series may contain a unit root or are close to the unit root case.

[Insert Table 4 here]

\subsubsection{Cointegration analysis}

In the second step of the strategy of Gil-Alana (2003) and Caporale and Gil-Alana (2004a and b), we consider now the possibility of the series being cointegrated. We consider first the classical standard cointegration. In Table 5, we can observe some results of the OLS regression of the pairwise (bivariate) cointegrating regression: $e_{t}=y_{t}-\widehat{\alpha}-\widehat{\beta} S P_{t}$ where $e_{t}$ is the estimated equilibrium error and $y_{t}$ is the foreign stock index. The results of the KPSS test show the rejection of the null hypothesis of stationarity of the estimated equilibrium errors and thus that the series are not cointegrated. This suggests that the US equity market and the equity markets in the UK, Germany, France, Brazil, Hong Kong, Argentina and Japan are not pairwise cointegrated during the considered period. The same results are found by Kanas (1998) for the period 03/01/83 - 29/11/96, in the case of UK, Germany and France ${ }^{7}$. The Johansen's tests exhibit mostly the same results, except for the case of Germany which appears pairwise cointegrated with the US stock market at the $5 \%$ level.

\section{[Insert Table 5 here]}

Concerning the fractional cointegration, Table 6 shows the results of onesided tests of Robinson (1994) on the estimated residuals $e_{t}$ from the cointegrating regression: we compute the statistic $\widehat{r}$, testing $H_{0}: \theta=0$ against the alternative $H_{1}: \theta<0$ in the model $(1-L)^{d+\theta} e_{t}=u_{t}$; as noted in Caporale and Gil-Alana (2004a and b), we can use the asymptotic Normal distribution because of the consistency of the cointegrating parameters and the desirable properties of Robinson's (1994) tests. Two cases are considered.

\section{[Insert Table 6 here]}

Case 1. No fractionally pairwise cointegration with the Standard \& Poor's index: Bovespa and Merval.

\footnotetext{
${ }^{7}$ Kanas (1998) uses the Dow Jones index for US stock market whereas we use the Standard and Poor's.
} 
In this case, the estimated residuals from the cointegrating regression are of a higher order of integration than that of the individual series; therefore, there does not exist a long run equilibrium relationship.

Case 2. Fractionally pairwise cointegration with the Standard \& Poor's index: CAC, Dax, FTSE, Hang Seng and Nikkei.

For these indices, the non-rejection values of $H_{0}: \theta=0$ occur always for values of $d<1$. This implies that the estimated residuals from the cointegrating regression are of a lower order of integration than that of the individual series; this thus shows that there exists the possibility of a long run equilibrium relationship. When we compare these indices, the results vary slightly; the minimum of the absolute values of the Robinson (1994) test statistics corresponds to the values of the long memory parameter $d$ equal to 0.725 for the CAC index, 0.775 for the Dax, and 0.800 for the Nikkei index, whatever the regressors. For the other two indices, the minimum of the absolute values of the statistics depend on the regressors: $0.700,0.675$ and 0.675 for the FTSE and 0.800, 0.750 and 0.775 for the Hang Seng index. On the whole, we can conclude that the fractional cointegration specification is accepted: a fractionally cointegrated relationship does exist between the Standard \& Poor's index and the other indices. The corresponding equilibrium errors exhibit thus hyperbolic mean reversion. The half-life estimates of residuals from the cointegrating regression are given in Table 7 and the optimal ARFIMA models obtained by using the BIC criterion are shown in Table 8 . Figures 3-7 depict the impulse response functions of the CAC, the Dax, the FTSE, the Hang Seng and the Nikkei indices; their estimated half-lives are given in Table 7 .

\author{
[Insert Tables 7 and 8 here] \\ [Insert Figures 2 to 6 here]
}

The shorter half-lifes correspond to the CAC (it is equal to 1.88) and the FTSE (about 3.7); they are longer for the HS (between 6.24 and 9.55), the DAX (8.74) and the NK (11.88).

\title{
4 Concluding remarks
}

Using linear cointegration tests, most of the empirical papers generally do not find pairwise cointegrating relationship between the US equity market and equity markets of the major industrial countries. However, adopting the two-step strategy of Gil-Alana (2003) and Caporale and Gil-Alana (2004a and b), based on the Robinson (1994) test, we show as a matter of fact that there exist pairwise fractional cointegration between the Standard \& Poor's 
index and the CAC, the Dax, the FTSE, the Hang Seng and the Nikkei indices; the corresponding equilibrium errors exhibit mean reversion, with half-life deviations lying between 2 and 12 days. It is worthwhile noting that emerging markets like Brazil and Argentina are not fractionally cointegrated with US stock market. These results suggest that there is some predictability of prices in the long-run (Winner-Loser effect) as well as in the short-run for the stock markets of industrialized countries, but also this evidence of fractional cointegration reduces, in the long-run, the potential benefits of international portfolio diversification. However, another important result is that these conclusions do not hold for some emerging countries.

\section{References}

[1] Ahlgren, N., Antell, J., 2002. Testing for cointegration between international stock prices, Applied Financial Economics 12, 851-861.

[2] Baillie, R.T., Bollerslev, T., 1994. Cointegration, fractional cointegration, and exchange rate dynamics. The Journal of Finance 49, 737-745.

[3] Bley, J., 2009. European stock market integration: Fact or fiction?, Int. Fin. Markets, Inst. and Money 19, 759-776.

[4] Campbell, J.Y., Mankiw, N.G., 1987. Are output fluctuations transitory?. Quarterly Journal of Economics 102, 857-880.

[5] Caporale, G.M., Gil-Alana, L.A., 2004a. Fractional cointegration and tests of present value models. Review of Financial Economics 13, 245258.

[6] Caporale, G.M., Gil-Alana, L.A., 2004b. Fractional cointegration and real exchange rates. Review of Financial Economics 13, 327-340.

[7] Caporale, G.M., Gil-Alana, L.A., 2007a. Mean reversion in the US treasury constant maturity rates. Centre for International Capital Markets, Discussion Paper No 2007-5.

[8] Caporale G.M., Gil-Alana L.A., 2007b. Mean reversion in the Nikkei, Standard \& Poor and Dow Jones stock market indices. Brunel University, Discussion Paper.

[9] Chan, K.C., Gup, B.E., Pan, M-S., 1997. International stock market efficiency and integration: a study of eighteen nations, Journal of Business Finance \& Accounting, 24(6). 
[10] Cheung, Y.W., Lai, K.S., 1993. A fractional cointegration analysis of purchasing power parity. Journal of Business and Economic Statistics $11,103-112$.

[11] Christensen, B., Nielson, M., 2006. Asymptotic normality of narrowband least squares in the stationary fractional cointegration model and volatility forecasting. Journal of Econometrics 133, 343-371.

[12] Corhay, A., Rad, A. T., Urbain, J.-P., 1993. Common Stochastic Trends in European Stock Markets, Economics Letters 42, 385-390.

[13] Davidson, J., 2005. Testing for fractional cointegration: The relationship between government popularity and economic performance in the UK. In: Diebolt, C., and Kyrtsou, C. (Eds.), New Trends in Macroeconomics. Springer Verlag.

[14] Davies, A., 2006. Testing for international equity market integration using regime switching cointegration techniques, Review of Financial Economics 15, 305-321.

[15] Diamandis, P.F., 2009. International stock market linkages: Evidence from Latin America, Global Finance Journal 20, 13-30.

[16] Dittman, I., 2001. Fractional cointegration of voting and non-voting shares. Applied Financial Economics 11, 321-332.

[17] Dunis, C.L., Shannon, G., 2005. Emerging markets of South-East and Central Asia: Do they still offer a diversification benefit? Journal of Asset Management, 6(3), 168-190.

[18] Fraser P., Oyefeso, O., 2005. US, UK and European Stock Market Integration, Journal of Business Finance \& Accounting, 32(1) \& (2).

[19] Garcia Pascual, A., 2003. Assessing European stock markets (co)integration, Economics Letters 78, 197-203

[20] Geweke, J., Porter-Hudak, S., 1983. The estimation and application of long memory time series models. Journal of Time Series Analysis 4 , 221-238.

[21] Gil-Alana, L.A., 2003. Testing of Fractional Cointegration in Macroeconomic Time Series, Oxford Bulletin of Economic and Statistics, 65(4) 
[22] Gil-Alana, L.A., Nazarski, M., 2007. Strong dependence in the nominal exchange rates of the Polish zloty. Applied Stochastic Models in Business and Industry 23, 97-116.

[23] Granger, C.W.J., 1986. Developments in the study of cointegrated economic variables, Oxford Bulletin of Economics and Statistics 48, 213228.

[24] Hassler, U., Marmol, F., Velasco, C., 2006. Residual log-periodogram inference for long run relationships. Journal of Econometrics 130, 165207.

[25] Huang, B-N., Fok, C. W., 2001. Stock market integration: an application of the stochastic permanent breaks model, Applied Economics Letters $8,725-729$.

[26] Johansen, S., 1988 Statistical analysis of cointegration vectors, Journal of Economics Dynamics and Control, 12, 231-54.

[27] Kanas, A., 1998. Linkages between the US and European equity markets: further evidence from cointegration tests. Applied Financial Economics $8,607-614$.

[28] Kasa, K., 1992. Common Stochastic Trends in International Stock Markets. Journal of Monetary Economics 29, 95-124.

[29] Kim, C., Phillips, P.C.B., 2001. Fully modified estimation of fractional cointegration models. Yale University.

[30] Kwiatowski, D., Phillips, P.C.B., Schmidt, P, Shin, Y., 1992. Testing the Null Hypothesis of Stationarity Against the Alternative of a Unit Root: How Sure Are We That Economic Time Series Have a Unit Root?. Journal of Econometrics 54, 159-178.

[31] Lucas, A., 1997. Strategic and Tactical Asset Allocation and the Effect of Long-Run Equilibrium Relations, Research Memorandum 1997-42, Vrije Universiteit Amsterdam.

[32] Li, X-M., 2006. A revisit of international stock market linkages: new evidence from rank tests for nonlinear cointegration, Scottish Journal of Political Economy, Vol. 53, No. 2.

[33] Marinucci, D., Robinson, P.M., 2001. Semiparametric fractional cointegration analysis. Journal of Econometrics 105, 225-247. 
[34] Nielsen, M., 2006. Local whittle analysis of stationary fractional cointegration and the implied realized volatility relation. Journal of Business and Economics Statistics, forthcoming.

[35] Olusi, O., Abdul-Majid, H., 2008. Diversification prospects in Middle East and North Africa (MENA) equity markets: a synthesis and an update, Applied Financial Economics 18, 1451-1463.

[36] Phylaktis, K., Ravazzolo, F., 2005. Stock market linkages in emerging markets:implications for international portfolio diversification, Int. Fin. Markets, Inst. and Money 15, 91-106.

[37] Pynnonen S., Knif, J., 1998. Common long-term and short-term price memory in two Scandinavian stock markets, Applied Financial Economics 8, 257-265.

[38] Rangvid, J., 2001. Increasing convergence among European stock markets? A recursive common stochastic trends analysis, Economics Letters 71, 383-389.

[39] Richards A.J., 1995. Comovements in national stock market returns: Evidence of predictability, but not cointegration, Journal of Monetary Economics 36, 631-654

[40] Robinson, P.M., 1994. Efficient tests of nonstationary hypotheses. Journal of the American Statistical Association 89, 1420-1437.,

[41] Robinson, P.M., Marinucci, D., 2003. Semiparametric frequency domain analysis of fractional cointegration. In: Robinson, P.M., (Ed.). Time Series with Long Memory. Oxford University Press, Oxford, 334-373.

[42] Robinson, P.M., Yajima, Y., 2002. Determination of cointegration rank in fractional systems. Journal of Econometrics 106, 217-241.

[43] Shimotsu, K., 2006. Exact local Whittle estimation of fractional integration with unknown mean and time trend. Working Paper N. 1061, Queen's University, Canada.

[44] Shin, Y., 1994. A residual based-test of the null of cointegration against the alternative of no cointegration. Econometric Theory 10, 91-115.

[45] Taylor, M. P., Tonks, I., 1989. The Internationalisation of Stock Markets and the Abolition of U.K. Exchange Control. Review of Economics and Statistics 71, 332-336. 
[46] Tse, Y., Anh, V., Tieng, A., 1999. No-cointegration test based on fractional differencing: Some Monte Carlo results. Journal of Statistical Planning and Inference 80, 257-267.

[47] Velasco, C., 2003. Gaussian semiparametric estimation of fractional cointegration. Journal of Time Series Analysis 24, 345-378. 


\section{Appendix}

The Lagrange Multiplier (LM) statistic proposed by Robinson (1994), called $\widehat{r}$, is given by:

$$
\widehat{r}=\left(\frac{T}{\widehat{A}}\right)^{1 / 2} \frac{\widehat{a}}{\widehat{\sigma}^{2}}
$$

where $T$ is the sample size and

$$
\begin{gathered}
\widehat{a}=\frac{-2 \pi}{T} \sum_{j=1}^{T-1} \psi\left(\lambda_{j}\right) g\left(\lambda_{j}, \widehat{\tau}\right)^{-1} I\left(\lambda_{j}\right) \\
\widehat{\sigma}^{2}=\frac{2 \pi}{T} \sum_{j=1}^{T-1} g\left(\lambda_{j}, \widehat{\tau}\right)^{-1} I\left(\lambda_{j}\right), \\
\widehat{A}=\frac{2}{T}\left[\sum_{j=1}^{T-1} \psi\left(\lambda_{j}\right)^{2}-\sum_{j=1}^{T-1} \psi\left(\lambda_{j}\right) \widehat{\varepsilon}\left(\lambda_{j}\right)^{\prime}\right. \\
\left.\times\left(\sum_{j=1}^{T-1} \widehat{\varepsilon}\left(\lambda_{j}\right) \widehat{\varepsilon}\left(\lambda_{j}\right)^{\prime}\right)^{-1} \sum_{j=1}^{T-1} \widehat{\varepsilon}\left(\lambda_{j}\right) \psi\left(\lambda_{j}\right)\right] \\
\widehat{\tau}=\underset{\tau \in T^{*}}{\arg \min } \widehat{\sigma}^{2}, \quad \psi\left(\lambda_{j}\right)=\log \left|2 \sin \frac{\lambda_{j}}{2}\right|, \quad \lambda_{j}=\frac{2 \pi j}{T} \\
\widehat{\varepsilon}\left(\lambda_{j}\right)=\frac{\partial}{\partial \tau} \log g\left(\lambda_{j}, \widehat{\tau}\right), \quad g(\lambda, \tau)=\frac{2 \pi}{\sigma^{2}} f\left(\lambda, \tau, \sigma^{2}\right)
\end{gathered}
$$

$f$ is the spectral density of $u_{t}, T^{*}$ is a suitable set of $\mathbb{R}^{k}$ and $I\left(\lambda_{j}\right)$ is the periodogram of

$$
\widehat{u}_{t}=(1-L)^{d} y_{t}-\widehat{\beta}^{\prime} W_{t}
$$

evaluated at $\lambda_{j}$ with

$$
W_{t}=(1-L)^{d} X_{t}
$$

and

$$
\widehat{\beta}=\left(\sum_{t=1}^{T} W_{t} W_{t}^{\prime}\right)^{-1} \sum_{t=1}^{T} W_{t}(1-L)^{d} y_{t} .
$$

Note that $\sigma^{2}$ is generally no longer the variance of $u_{t}$, but rather the variance of the innovation sequence in a normalized Wold representation of $u_{t}$. Robinson (1994) shows that $\widehat{r}$ has a standard asymptotic distribution under some regularity conditions:

$$
\widehat{r} \underset{d}{\longrightarrow} N(0,1) \quad \text { as } T \longrightarrow \infty .
$$


Table 1: Descriptive statistics on returns

\begin{tabular}{l|rr} 
& Mean & Std Error \\
\hline \hline$B O V_{t}$ & 0.09187 & 1.9085 \\
$C A C_{t}$ & 0.00770 & 1.3782 \\
$D A X_{t}$ & 0.01157 & 1.5146 \\
$F T S E_{t}$ & 0.00144 & 1.1347 \\
$H S_{t}$ & 0.03487 & 1.4092 \\
$N K_{t}$ & 0.00132 & 1.3462 \\
$M E R V_{t}$ & 0.06687 & 2.0891 \\
$S P_{t}$ & 0.00499 & 1.1035 \\
\hline \hline
\end{tabular}


Table 2: KPSS test on each individual series

\begin{tabular}{lrr|lrr} 
& $K P S S_{0}$ & $K P S S_{6}$ & & $K P S S_{0}$ & $K P S S_{6}$ \\
\hline \hline$B O V_{t}$ & 39.947 & 5.746 & $\Delta B O V_{t}$ & 0.101 & 0.105 \\
$C A C_{t}$ & 41.821 & 5.998 & $\Delta C A C_{t}$ & 0.125 & 0.150 \\
$D A X_{t}$ & 46.395 & 6.650 & $\Delta D A X_{t}$ & 0.112 & 0.120 \\
$F T S E_{t}$ & 52.790 & 7.577 & $\Delta F T S E_{t}$ & 0.068 & 0.089 \\
$H S_{t}$ & 44.565 & 6.398 & $\Delta H S_{t}$ & 0.110 & 0.108 \\
$N K_{t}$ & 50.161 & 7.190 & $\Delta N K_{t}$ & 0.144 & 0.149 \\
$M E R V_{t}$ & 31.346 & 4.506 & $\Delta M E R V_{t}$ & 0.094 & 0.085 \\
$S P_{t}$ & 47.549 & 6.831 & $\Delta S P_{t}$ & 0.068 & 0.080 \\
\hline \hline
\end{tabular}

Note: The period is January 4, 1999 - March 6, $2008(T=2389) . K P S S_{i}$ is the $\tau$-statistic of order $i$ of the Kwiatowski, Phillips, Schmidt and Shin (1992) test; the critical values are: 0.119 (10\%), $0.146(5 \%)$ and $0.216(1 \%)$. 
Table 3: Feasible local Whittle estimation of each variable

\begin{tabular}{c|cccc} 
& $\widehat{d}$ & $\widehat{\sigma}$ & $d_{l}$ & $d_{u}$ \\
\hline \hline$B O V_{t}$ & 1.027 & 0.040 & 0.949 & 1.106 \\
$C A C_{t}$ & 0.995 & 0.040 & 0.916 & 1.073 \\
$D A X_{t}$ & 1.015 & 0.040 & 0.937 & 1.093 \\
$F T S E_{t}$ & 0.964 & 0.040 & 0.885 & 1.042 \\
$H S_{t}$ & 1.018 & 0.040 & 0.939 & 1.096 \\
$N K_{t}$ & 0.993 & 0.040 & 0.915 & 1.072 \\
$M E R V_{t}$ & 1.057 & 0.040 & 0.979 & 1.136 \\
$S P_{t}$ & 0.994 & 0.040 & 0.915 & 1.072 \\
\hline \hline
\end{tabular}

Note: The period is January 4, 1999 - March 6, $2008(T=2389)$. $\widehat{d}$ is FELW estimator developed by Shimotsu (2006) of the long memory parameter; $\widehat{\sigma}$ is the estimated standard-errors of the Shimotsu estimator; $d_{l}$ and $d_{u}$ are the lower and upper bounds of the $95 \%$ confidence intervals. For the feasible local Whittle estimation (see Shimotsu (2006)), $m$ is chosen to be $m=T^{0.65}$ with $T$ is the sample size. 
Table 4: Order of integration of each variable with the test of Robinson (1994)

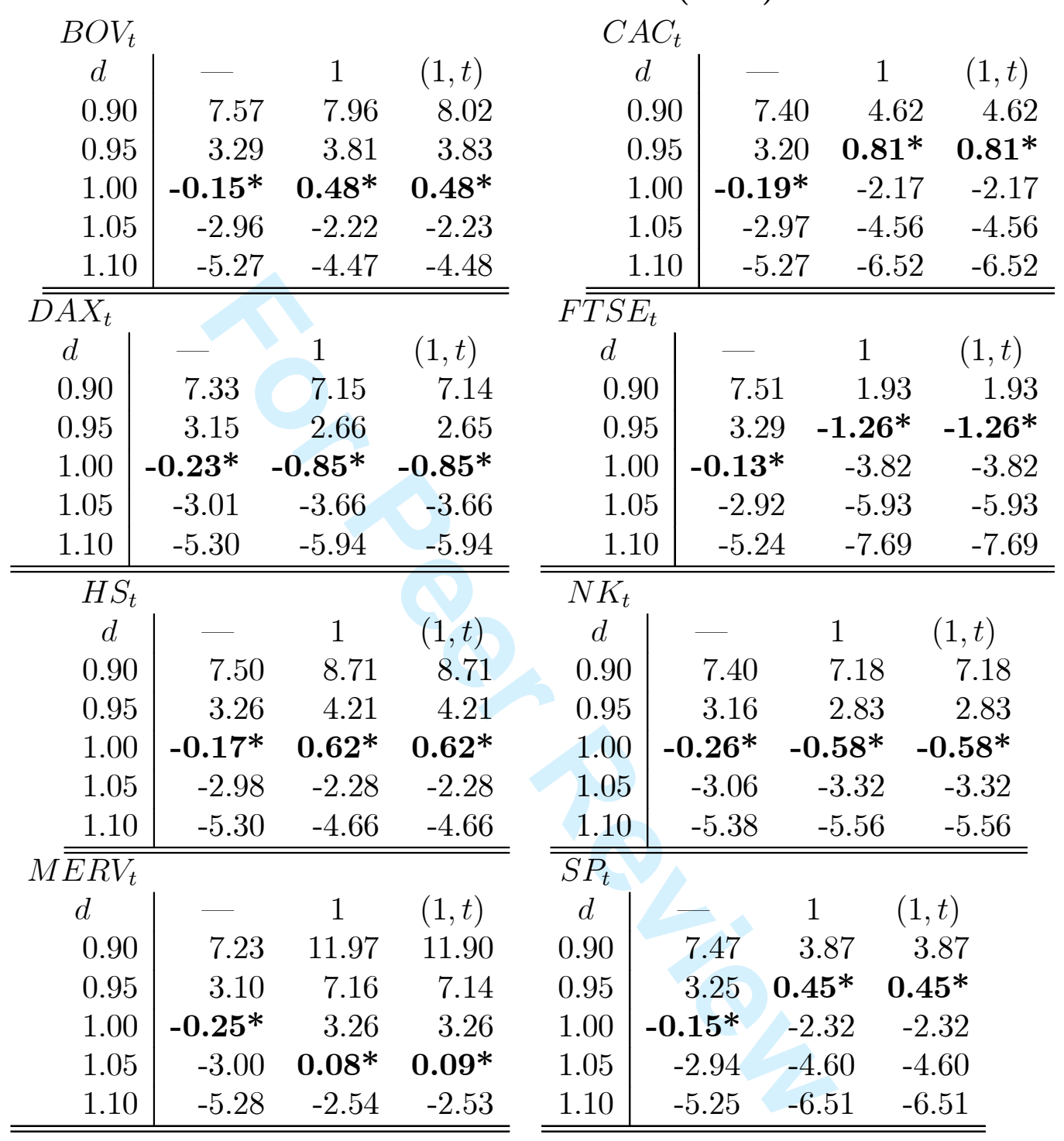

Note: The period is January 4, 1999 - March 6, $2008(T=2389)$. We consider only the test where $u_{t}$ is assumed to be white noise, with different specifications: with no regressors $(-)$, with an intercept $(1)$ and with a linear trend $((1, t))$. In bold: the minimum (in absolute value) of the Robinson (1994) test statistic. ${ }^{*}$ : nonrejection values of the null hypothesis $H_{0}: \theta=0$ at the $95 \%$ significance level (the critical value is 1.65 in absolute value). 
Table 5: Cointegration and Johansen's cointegration test

\begin{tabular}{|c|c|c|c|c|c|c|}
\hline & $\widehat{\alpha}$ & $\widehat{\beta}$ & $K P S S_{0}$ & $K P S S_{2}$ & $r \leq 1$ & $r=0$ \\
\hline 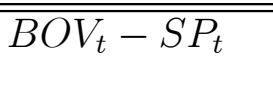 & $\begin{array}{c}-1.846 \\
(0.19)\end{array}$ & $\begin{array}{c}1.995 \\
(0.06)\end{array}$ & $\bar{~} 18.838$ & 6.405 & 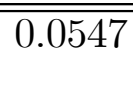 & 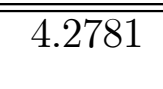 \\
\hline$C A C_{t}-S P_{t}$ & $\begin{array}{c}-0.537 \\
(0.03)\end{array}$ & $\begin{array}{l}1.358 \\
(0.01)\end{array}$ & 19.377 & 6.523 & 3.5150 & 15.1261 \\
\hline$D A X_{t}-S P_{t}$ & $\begin{array}{c}-1.711 \\
(0.04)\end{array}$ & $\begin{array}{l}1.756 \\
(0.01)\end{array}$ & 21.138 & 7.121 & 3.1357 & $17.9492^{*}$ \\
\hline$F T S E_{t}-S P_{t}$ & $\begin{array}{c}0.473 \\
(0.02)\end{array}$ & $\begin{array}{l}1.055 \\
(0.00)\end{array}$ & 18.229 & 6.219 & 1.6811 & 5.9188 \\
\hline$H S_{t}-S P_{t}$ & $\begin{array}{c}-0.399 \\
(0.06)\end{array}$ & $\begin{array}{c}1.474 \\
(0.02)\end{array}$ & 9.099 & 3.102 & 0.1568 & 3.6410 \\
\hline$N K_{t}-S P_{t}$ & $\begin{array}{c}-0.369 \\
(0.04)\end{array}$ & $\begin{array}{l}1.455 \\
(0.01)\end{array}$ & 9.825 & 3.331 & 0.3735 & 10.2559 \\
\hline$M E R V_{t}-S P_{t}$ & $\begin{array}{c}-2.145 \\
(0.25) \\
\end{array}$ & $\begin{array}{c}1.640 \\
(0.08) \\
\end{array}$ & 21.965 & 7.351 & 3.3482 & 10.0086 \\
\hline
\end{tabular}

Note: The period is January 4, 1999 - March 6, $2008(T=2389) . \widehat{\alpha}$ and $\widehat{\beta}$ are the estimated values of the coefficients in the cointegrating regression $y_{t}=\alpha+\beta S P_{t}+$ noise where $y_{t}$ is one of the seven stock indices under study (the series are expressed in logarithm); the estimation method is the ordinary least squares and standard errors are in parenthesis. $K P S S_{i}$ is the statistic of order $i$ of the Kwiatowski, Phillips, Schmidt and Shin (1992) test; the critical values are given in Shin (1994).

The last two columns presents the results of Johansen's cointegration test, using 15 lags and an unrestricted constant. Critical values for trace test are obtained from Johansen (1988) and given by

\begin{tabular}{|l|l|l|}
\hline Significance level & $r \leq 1$ & $r=0$ \\
\hline $5 \%$ & 3.76 & 15.41 \\
\hline $1 \%$ & 6.65 & 20.04 \\
\hline
\end{tabular}

where $r$ denotes the number of cointegrating vectors. 
Table 6: Robinson (1994) test on estimated residuals from the cointegrating regression

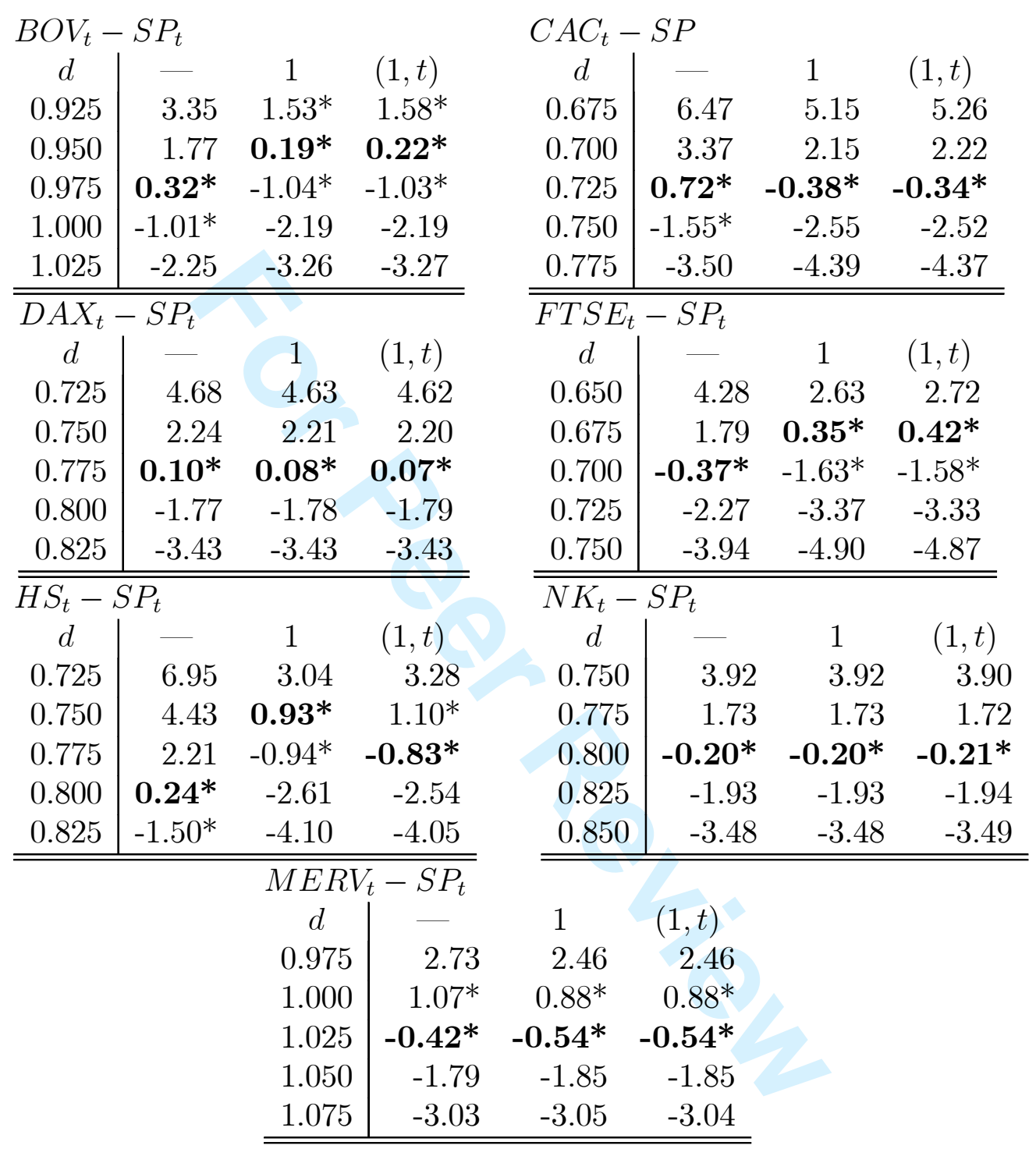

Note: The period is January 4, 1999 - March 6, $2008(T=2389)$. We consider only the test where $u_{t}$ is assumed to be white noise, with different specifications: with no regressors $(-)$, with an intercept $(1)$ and with a linear trend $((1, t))$. In bold: the minimum (in absolute value) of the Robinson (1994) test statistic. *: rejections of the null hypothesis of "no cointegration" at the $95 \%$ significance level (the critical value is 1.65 in absolute value). 
Table 7: Half-life estimates of the residuals from the cointegrating regression

\begin{tabular}{l|rrr} 
& \multicolumn{1}{|c}{1} & $(1, t)$ \\
\hline \hline$C A C$ & 1.88 & 1.88 & 1.88 \\
$D A X$ & 8.74 & 8.74 & 8.74 \\
$F T S E$ & 3.75 & 3.66 & 3.66 \\
$H S$ & 6.24 & 7.55 & 9.55 \\
$N K$ & 11.88 & 11.88 & 11.88 \\
\hline \hline
\end{tabular}

Note: The different specifications are: with no regressors $(-)$, with an intercept $(1)$ and with a linear trend $((1, t))$. The half-life is estimated by using a linear interpolation as follows: if $k$ is such that $I R F[k] \geq 0.5 \geq \operatorname{IRF}[k+1]$ then the linear approximation for the half-life estimate is given by

$$
h=(0.5-(k+1) \operatorname{IRF}[k]+k I R F[k+1]) /(\operatorname{IRF}[k+1]-\operatorname{IRF}[k]) .
$$


Table 8: Optimal ARFIMA models obtained by using the BIC criterion

\begin{tabular}{|c|c|}
\hline $\mathrm{CAC}$ & $\begin{array}{l}(1-L)^{0.725}\left(1+\underset{(0.024)}{0.090} L+\underset{(0.033)}{0.782} L^{2}+\underset{(0.031)}{0.086} L^{3}\right. \\
\left.+\underset{(0.021)}{0.033 L^{4}}\right) e_{t}=\left(1-\underset{(0.105)}{0.232} L-\underset{(0.476)}{0.803 L^{2}}\right) \varepsilon_{t}\end{array}$ \\
\hline$\overline{\overline{\text { DAX }}}$ & $(1-L)^{0.775} e_{t}=\left(1-\underset{(0.020)}{0.048 L}+\underset{(0.020)}{\left.0.029 L^{2}\right) \varepsilon_{t}}\right.$ \\
\hline \multirow{2}{*}{ FTSE } & $\begin{array}{l}\text { with no regressors }(-): \\
(1-L)^{0.7}\left(1-\underset{(0.008)}{0.054 L}+\underset{(0.008)}{\left.0.909 L^{2}\right) e_{t}=}\right. \\
\left(1-\underset{(0.001)}{0.045 L}-\underset{(0.008)}{0.903 L^{2}}+\underset{(0.001)}{\left.0.139 L^{3}\right) \varepsilon_{t}}\right. \\
\left(\begin{array}{l}0.045 \\
(1)\end{array}\right.\end{array}$ \\
\hline & 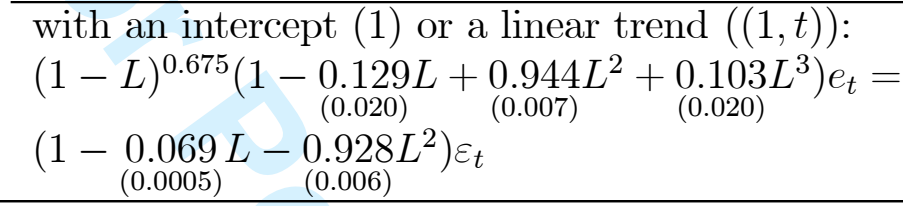 \\
\hline \multirow{3}{*}{ HS } & $\begin{array}{l}\text { with no regressors }(-) \text { : } \\
(1-L)^{0.75} e_{t}=(1-0.017) \varepsilon_{t}\end{array}$ \\
\hline & $\begin{array}{l}\text { with an intercept }(1) \text { : } \\
(1-L)^{0.775} e_{t}=\left(1-\underset{(0.020)}{0.048)} \varepsilon_{t}\right.\end{array}$ \\
\hline & $\begin{array}{l}\text { with a linear trend }((1, t)) \text { : } \\
(1-L)^{0.8} e_{t}=\left(1-\underset{(0.021)}{0.077) \varepsilon_{t}}\right.\end{array}$ \\
\hline NK & $(1-L)^{0.8} e_{t}=\left(1-\underset{(0.021)}{0.053 L}+\underset{(0.020)}{\left.0.015 L^{2}\right) \varepsilon_{t}}\right.$ \\
\hline
\end{tabular}


1

2

3

4

5

6

7

8

9

10

11

12

13

14

15

16

17

18

19

20

21
Figure 1. The logarithmic stock markets indices
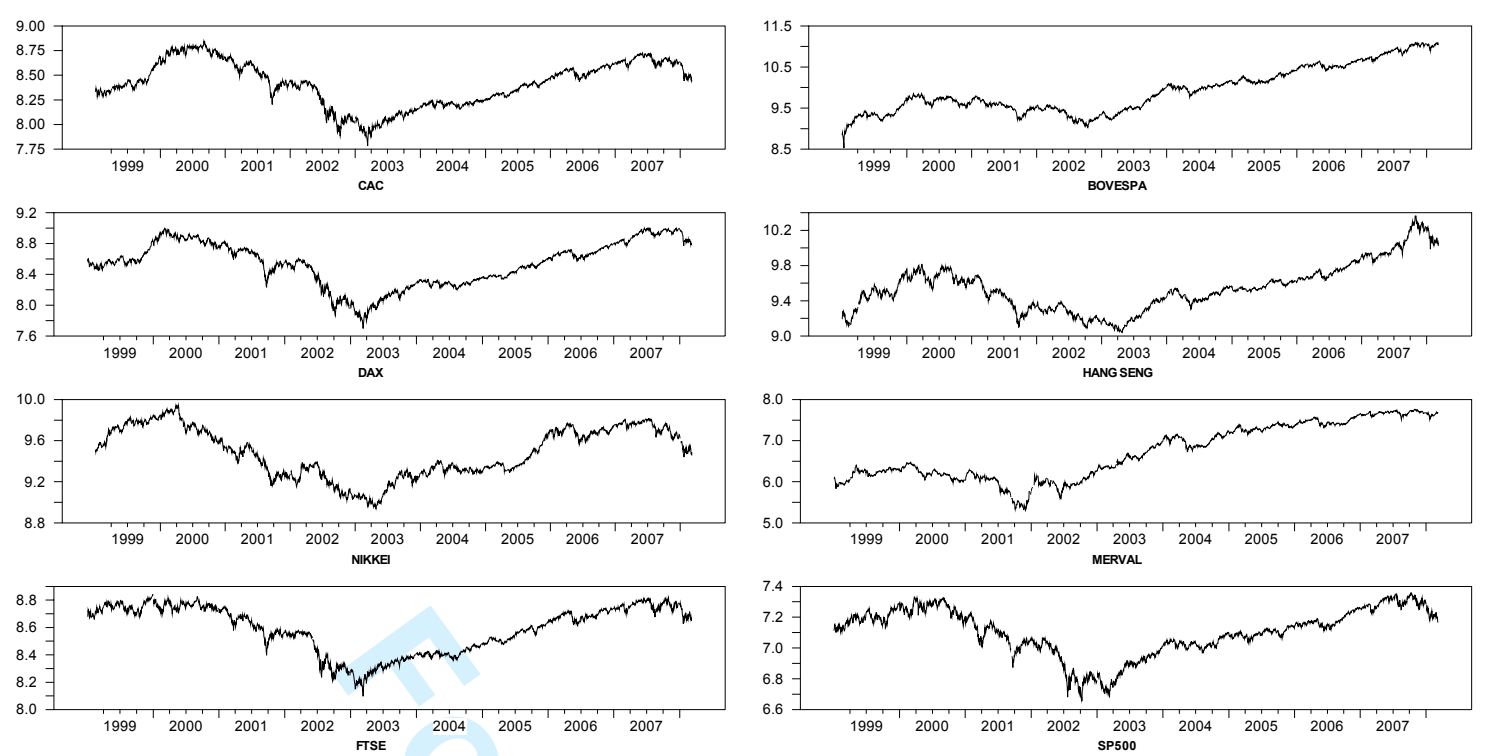
Figure 2. The impulse response function of the estimated residuals from the cointegrating regression $\left(C A C_{t} S P_{t}\right)$

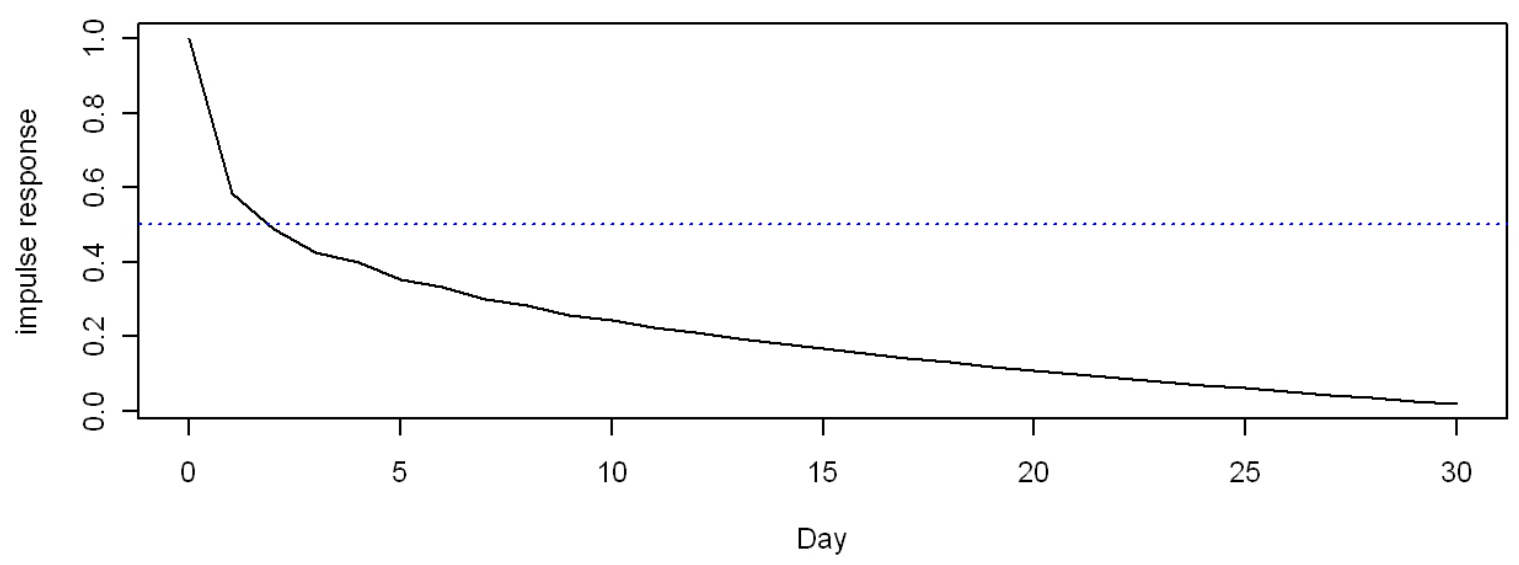


Figure 3. The impulse response function of the estimated residuals from the cointegrating regression $\left(D A X_{t} S P_{t}\right)$

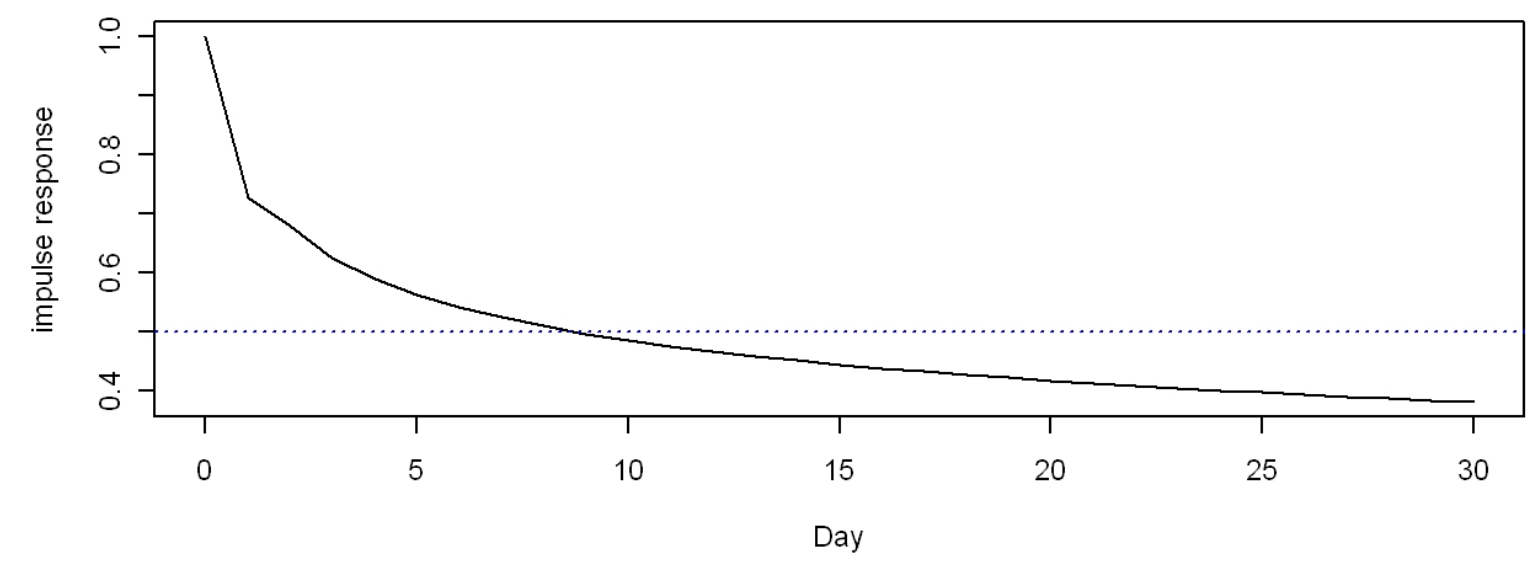

Editorial Office, Dept of Economics, Warwick University, Coventry CV4 7AL, UK 
Figure 4. The impulse response function of the estimated residuals from the cointegrating regression $\left(\mathrm{FTSE}_{t}-\mathrm{SP}_{t}\right)$

with no regressor $(-)$

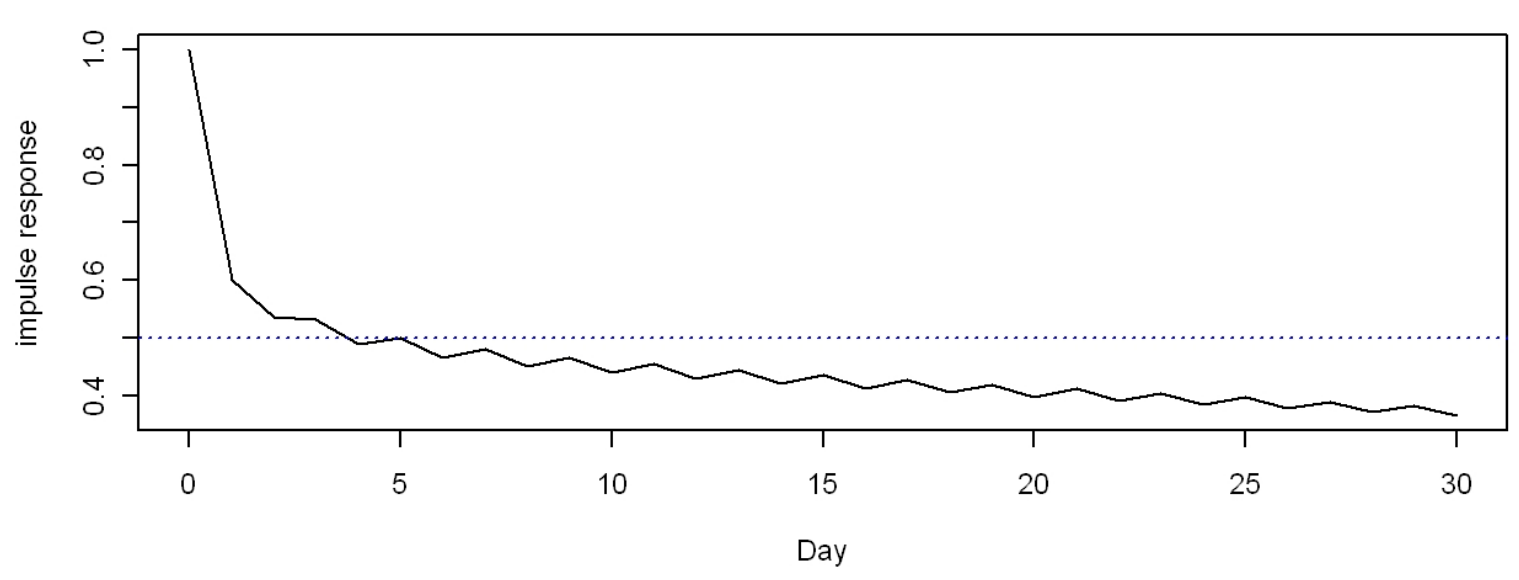

with an intercept $(1)$ or a linear trend $((1, t))$

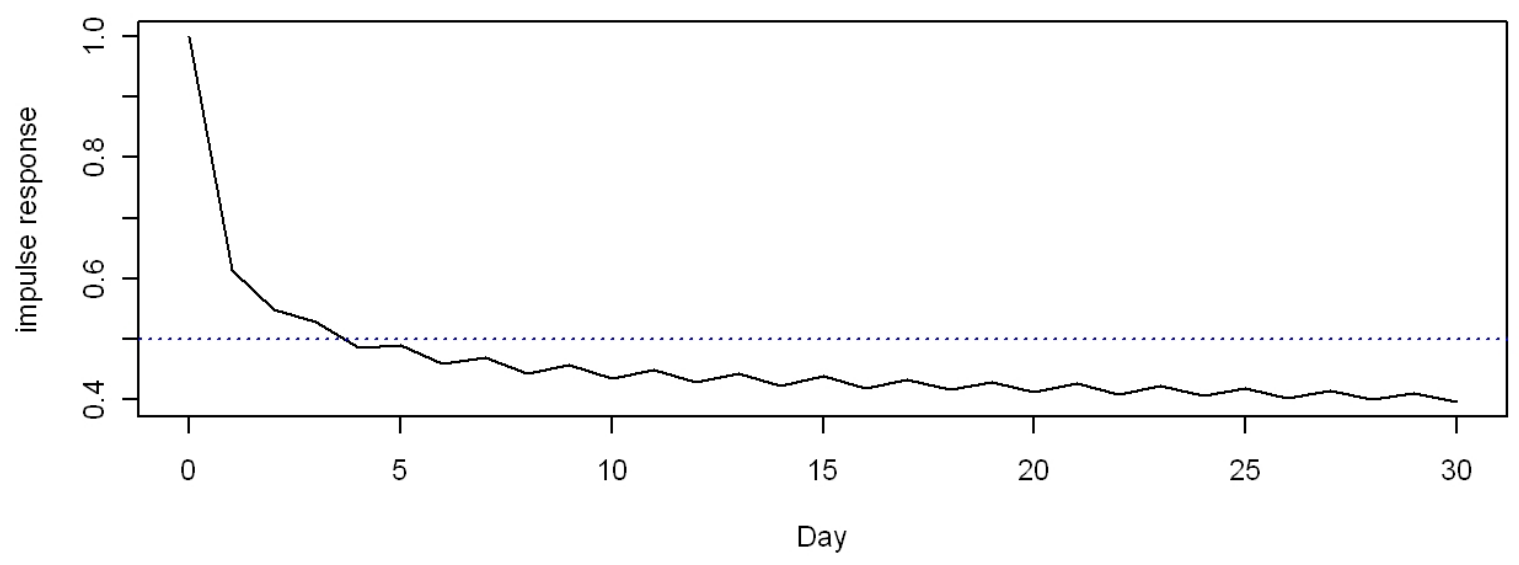

Editorial Office, Dept of Economics, warwick University, Coventry CV4 7AL, UK 
Figure 5. The impulse response function of the estimated residuals from the cointegrating regression $\left(H S_{t} S P_{t}\right)$

with no regressor (一)

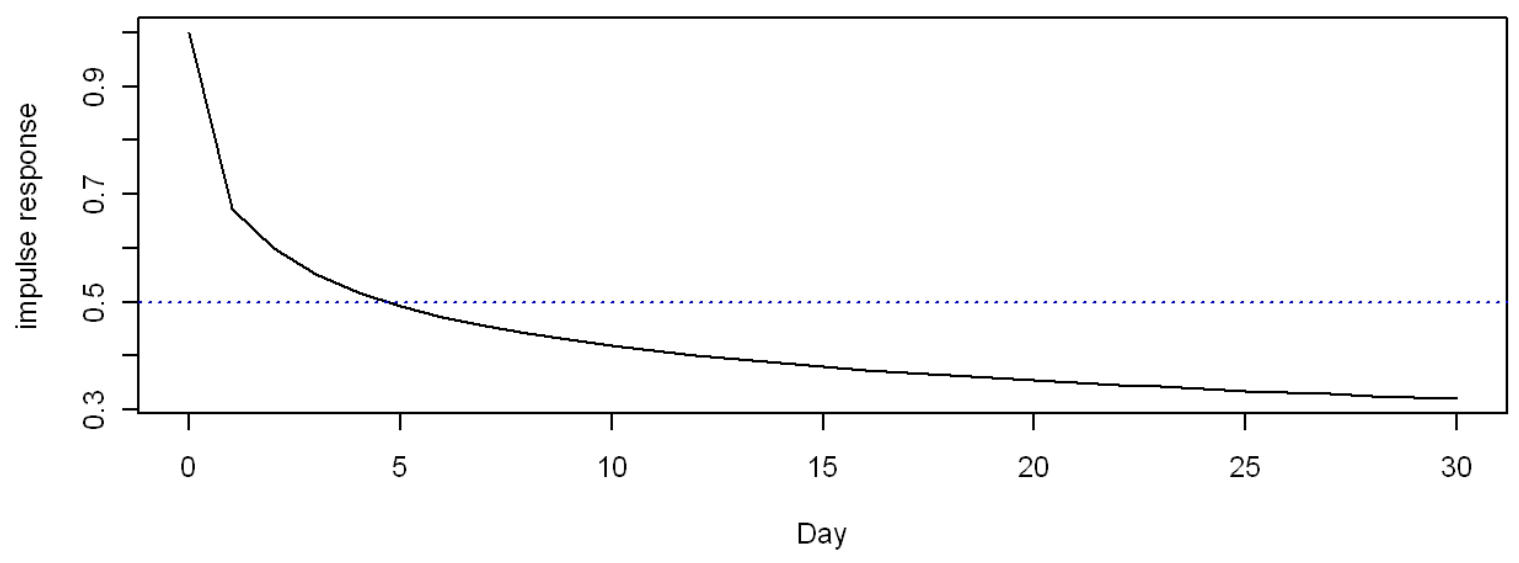

with an intercept (1)

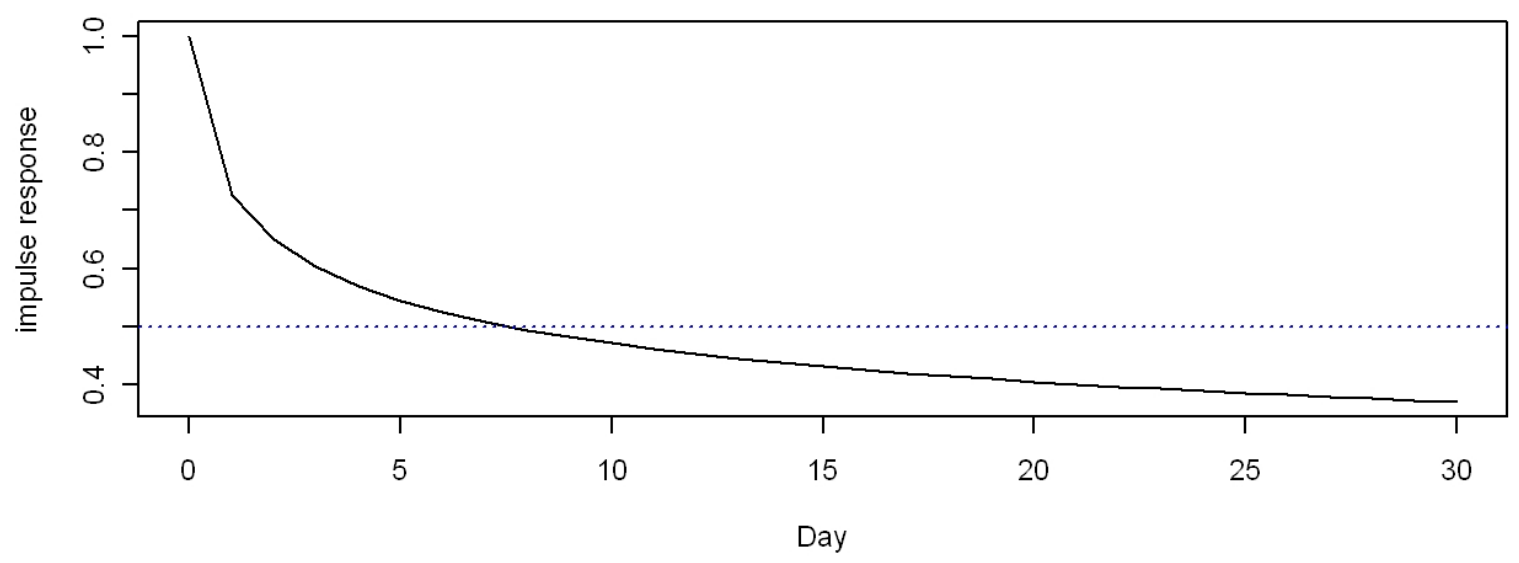

with a linear trend $((1, t))$

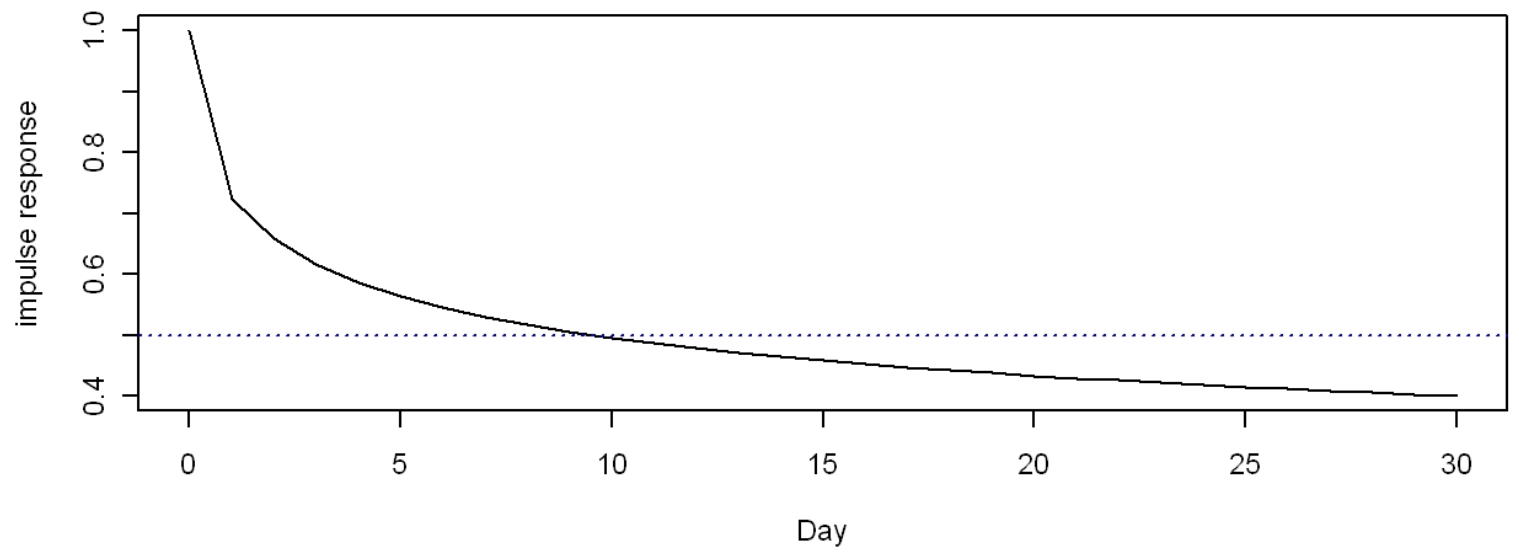

Editorial Office, Dept of Economics, Warwick University, Coventry CV4 7AL, UK 
Figure 6. The impulse response function of the estimated residuals from the cointegrating regression $\left(N K_{t} S P_{t}\right)$

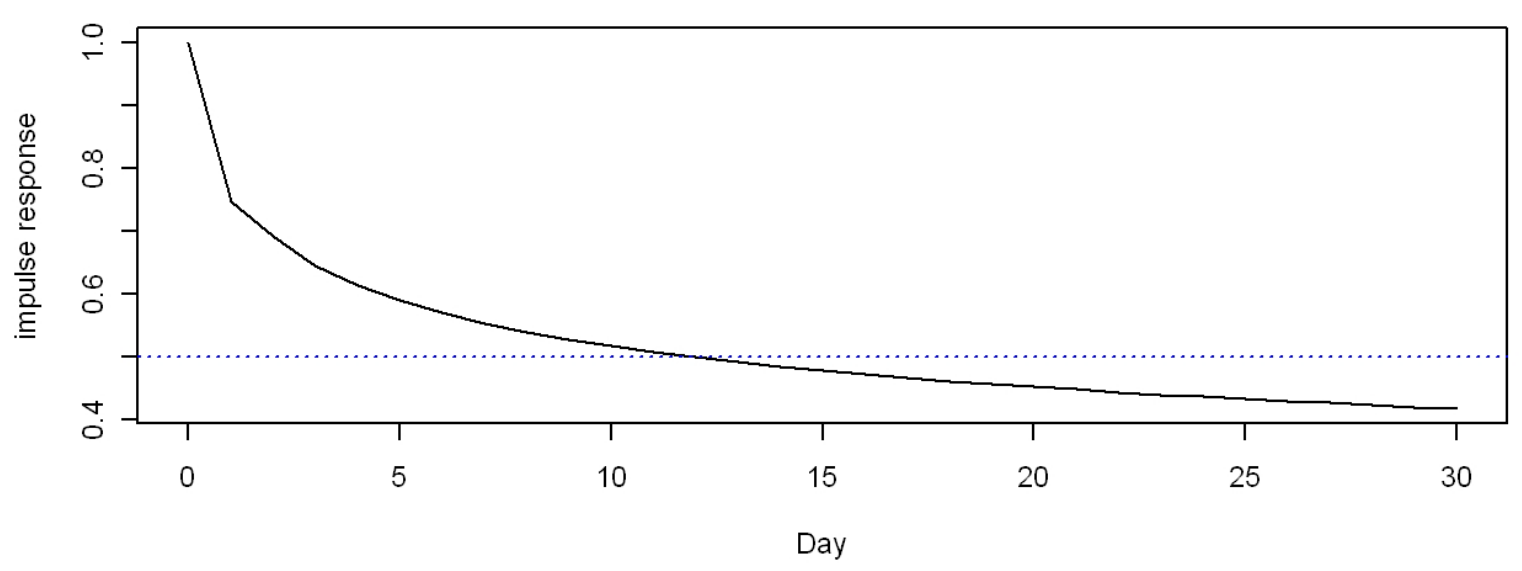

